Article

\title{
Rapid, Single-Step Protein Encapsulation via Flash NanoPrecipitation
}

\author{
Shani L. Levit, Rebecca C. Walker and Christina Tang *(1) \\ Chemical and Life Science Engineering Department, Virginia Commonwealth University, Richmond, \\ VA 23284-3028, USA \\ * Correspondence: ctang2@vcu.edu
}

Received: 24 July 2019; Accepted: 23 August 2019; Published: 27 August 2019

check for updates

\begin{abstract}
Flash NanoPrecipitation (FNP) is a rapid method for encapsulating hydrophobic materials in polymer nanoparticles with high loading capacity. Encapsulating biologics such as proteins remains a challenge due to their low hydrophobicity $(\log \mathrm{P}<6)$ and current methods require multiple processing steps. In this work, we report rapid, single-step protein encapsulation via FNP using bovine serum albumin (BSA) as a model protein. Nanoparticle formation involves complexation and precipitation of protein with tannic acid and stabilization with a cationic polyelectrolyte. Nanoparticle self-assembly is driven by hydrogen bonding and electrostatic interactions. Using this approach, high encapsulation efficiency (up to $\sim 80 \%$ ) of protein can be achieved. The resulting nanoparticles are stable at physiological $\mathrm{pH}$ and ionic strength. Overall, FNP is a rapid, efficient platform for encapsulating proteins for various applications.
\end{abstract}

Keywords: Flash NanoPrecipitation; nanoparticles; polyethylenimine; self-assembly; tannic-acid; electrostatic interactions; protein encapsulation

\section{Introduction}

Flash NanoPrecipitation (FNP) is a versatile method to incorporate hydrophobic drugs, dyes, or inorganic nanoparticles with a hydrophobic coating into polymeric nanoparticles via rapid mixing achieved with confined impinging jets [1]. Typically, nanoparticle self-assembly involves precipitation of the supersaturated hydrophobic material via nucleation and growth as well as adsorption of a micellizing amphiphilic block copolymer. The resulting nanoparticles are sterically stabilized with a hydrophobic core-hydrophilic shell structure [1,2]. Due to the rapid precipitation rate and strong hydrophobic interaction with the hydrophobic block of the amphiphilic block copolymer necessary for stabilization, the use of FNP has generally been limited to encapsulation of hydrophobic materials $(\log P>6)[3]$. Due to the increasing emphasis on biologically derived therapeutics [4] such as proteins and peptides, encapsulation to prevent rapid clearance from natural mechanisms and enzymatic degradation of the biologics $[5,6]$ via FNP is of considerable interest.

Encapsulation of less hydrophobic materials $(\log P<6)[7-10]$ using FNP has been achieved via in situ complexation [7-10]. For example, hydrophobic ion pairs [9] or insoluble coordination complexes can be formed during mixing and stabilized with an amphiphilic block copolymer [10]. To encapsulate peptides, hydrophilic imaging agents, and small proteins ( 14 kDa), inverse Flash NanoPrecipitation (iFNP) has recently been reported [11,12]. In iFNP, the biologic and the amphiphilic block copolymer are solubilized in a polar organic solvent (e.g., dimethyl sulfoxide) and rapidly mixed with a miscible nonpolar solvent (e.g., acetone or chloroform) which leads to precipitation of the biologic, adsorption of the hydrophilic block, and stabilization by the hydrophobic block in the nonpolar solvent. These initial particles, with a hydrophilic core and hydrophobic coating, are then crosslinked for stabilization 
and dispersed in an appropriate solvent for a second FNP step for encapsulation within a second block copolymer [11,12]. While promising, this approach inherently requires multiple processing steps.

Another approach to encapsulate biologics has been Flash Nanocomplexation in which polyelectrolytes complex with biologics (e.g., negatively charged DNA) to impart stability. For gene delivery, Santos et al. stabilized DNA with linear polyethylenimine (lPEI) $(22 \mathrm{kDa}$ ) via rapid mixing [13]. This approach of leveraging electrostatic interactions has been successful for strong polyelectrolytes such as DNA. Use of this approach for encapsulation of diffusely charged, globular proteins has not yet been established.

Therefore, we investigate a single-step method for encapsulation of proteins via FNP. We use bovine serum albumin (BSA) as a model protein and form an insoluble precipitate in situ with tannic acid [14-16]. We study various stabilizers (i.e., an amphiphilic block copolymer and a polyelectrolyte). The effects of formulation parameters e.g., stabilizer concentration, molecular weight, $\mathrm{pH}$, and ionic strength on nanoparticle size, zeta potential, stability, protein encapsulation efficiency are discussed.

\section{Materials and Methods}

\subsection{Materials}

ACS grade tannic acid (TA), calcium chloride $\left(\mathrm{CaCl}_{2}\right)$, and ACS grade hydrochloric acid $(\mathrm{HCl})$ were purchased from Sigma-Aldrich (St. Louis, MO, USA). The branched polyethylenimine (PEI) with weight average molecular weight $\left(\mathrm{M}_{\mathrm{W}}\right)$ of $2000 \mathrm{~g} / \mathrm{mol}$ and 10,000 g/mol, were obtained from PolySciences (Warrington, PA, USA), and $\mathrm{M}_{\mathrm{W}}=750,000 \mathrm{~g} / \mathrm{mol} 50 \%(\mathrm{w} / \mathrm{v})$ in $\mathrm{H}_{2} \mathrm{O}$ was obtained from Sigma-Aldrich (St. Louis, MO, USA). Bovine serum albumin (BSA), ACS grade acetone, HPLC grade tetrahydrofuran (THF), diethyl ether, ammonium hydroxide $\left(\mathrm{NH}_{4} \mathrm{OH}\right)(\mathrm{aq} .10 \% \mathrm{v} / \mathrm{v})$, and ACS certified sodium chloride $(\mathrm{NaCl})$ were obtained from Fisher Scientific (Pittsburg, PA, USA). These reagents were used as received. Phosphate-buffered saline (PBS) was made with $156 \mathrm{mM} \mathrm{NaCl}, 10 \mathrm{mM}$ sodium phosphate dibasic anhydrous $\left(\mathrm{Na}_{2} \mathrm{HPO}_{4}\right.$, Fisher Scientific, Pittsburg, PA, USA), and $2 \mathrm{mM}$ potassium phosphate monobasic $\left(\mathrm{KH}_{2} \mathrm{PO}_{4}\right.$, Fisher Scientific, Pittsburg, PA, USA). Prior to use, BioRad Protein Assay Dye Reagent (Bradford dye, BioRad, Hercules, CA, USA) was filtered with a $0.45 \mu \mathrm{m}$ PTFE filter (Fisher Scientific, Pittsburg, PA, USA) and diluted 4-fold with deionized water. Additionally, polystyrene-b-polyethylene glycol (1600-b-500 g/mol) (PS-b-PEG) obtained from Polymer Source (Product No. P13141-SEO, Montreal, Canada) was dissolved in THF $(500 \mathrm{mg} / \mathrm{mL})$ and precipitated in diethyl ether (1:20 v:v THF:ether). The PS-b-PEG was recovered by centrifuging, decanting, and drying under vacuum at room temperature for two days as previously described [17].

\subsection{Nanoparticle Preparation}

Flash NanoPrecipitation (FNP) was performed with a hand-operated confined impinging jet (CIJ) mixer similar to previous reports [10]. Using the amphiphilic block copolymer stabilizer, PS-b-PEG was dissolved with TA $(5 \mathrm{mg} / \mathrm{mL})$ in acetone by sonication $\left(\sim 40{ }^{\circ} \mathrm{C}\right)$ and rapidly mixed with BSA dispersed in water $(9 \mathrm{mg} / \mathrm{mL}$ or $20 \mathrm{mg} / \mathrm{mL}$ ). The block copolymer to core material (BSA/TA) ratio was 2:1 by mass. The effluent from the CIJ mixer was immediately diluted in deionized water to maintain an acetone:water volume ratio of 1:9.

To use PEI as a stabilizer, TA $(5 \mathrm{mg} / \mathrm{mL})$ was dissolved in acetone and rapidly mixed with BSA dispersed in water $(9 \mathrm{mg} / \mathrm{mL})$; the mixer effluent was immediately diluted into PEI dispersed in water. The amount of PEI was varied relative to the mass of BSA/TA to achieve a final ratio PEI:BSA/TA of 1:1, 2:1, or 3:1 by mass. The volume of aqueous PEI was set to maintain a final acetone/water ratio of 1:9 by volume. To determine the role of TA, FNP was performed without TA using PEI as a stabilizer by rapidly mixing BSA dispersed in water with acetone and immediately diluting with PEI dispersed in water. In some cases, the ionic strength or the $\mathrm{pH}$ of the aqueous BSA stream was adjusted with $\mathrm{HCl}$ and $\mathrm{NH}_{4} \mathrm{OH}$ to achieve $\mathrm{pH}$ values between 2 and 10. In some cases following FNP, dialysis was performed to remove the organic solvent using regenerated cellulose tubing with a molecular weight 
cutoff of 6-8 kD MWCO (Spectra/Por, Spectrum Laboratories, Houston, TX, USA) against deionized water at a ratio of 1:100. The bath water was replaced four times in a 24-hour period.

\subsection{Nanoparticle Characterization}

The size and zeta potential of the resulting nanoparticle dispersions were measured after formulation with a Malvern Zetasizer ZS with a backscatter detection angle of $173^{\circ}$ (Malvern Instruments Ltd., Malvern, United Kingdom). The intensity average particle size and distribution are reported using normal resolution mode with an average of 4 measurements. The polydispersity index (PDI) is used as a measure of the breadth of the particle distribution defined from the moments of the cumulant fit of the autocorrelation function calculated by the instrument software as previously described. Nanoparticles with a PDI below 0.300 were considered uniform [10,18].

To assess nanoparticle stability, the $\mathrm{pH}$ of the nanoparticle dispersions following FNP was adjusted between $\mathrm{pH} 2$ and 10 with $\mathrm{HCl}$ or $\mathrm{NH}_{4} \mathrm{OH}$. The size and zeta potential were tracked by DLS for up to a week. Additionally, the effect of ionic strength on particle stability by adding $\mathrm{NaCl}$ or $\mathrm{CaCl}_{2}(10$ to $300 \mathrm{mM}$ ) after FNP and the resulting size and zeta potential were tracked for $24 \mathrm{~h}$.

\subsection{Protein Quantification}

The amount of protein encapsulated in the resulting nanoparticles was quantified using a Bradford assay. After FNP, nanoparticles were recovered by centrifugal filtration (Amicon Ultracel 50K, 50,000 NMWL, Merck Millipore Ltd., Burlington, MA, USA). Briefly, filters were centrifuged (5804 R 15 amp. version, Eppendorf, Hamburg, Germany) at $4000 \mathrm{rpm}$ for 30-40 min. The recovered nanoparticles were separated from the supernatant. The recovered particles were washed 3 times with acetone $(1 \mathrm{~mL})$ to precipitate the BSA and solubilize the other nanoparticle components. The precipitated BSA was recovered from the acetone soluble nanoparticle components by centrifugation (10,000 rpm for 5-10 min) and decanting the acetone supernatant. The recovered protein was redispersed in water. A Bradford assay was performed on the sample following the manufacture's protocol. Briefly, $10 \mu \mathrm{L}$ of sample and $200 \mu \mathrm{L}$ of Bradford dye were added to 96-well plate and measured with a microplate reader (VersaMax ELISA microplate reader, Molecular Devices, San Jose, CA, USA or Cytation 3 multi-mode reader, BioTek, Winooski, VT, USA) at a wavelength of $595 \mathrm{~nm}$. Performing the procedure with a known amount of BSA, we confirmed $98 \pm 3 \%$ protein recovery (Table S1).

\section{Results and Discussion}

Tannins such as tannic acid (TA) are known to precipitate proteins. Thus, to encapsulate proteins via Flash NanoPrecipitation (FNP), our approach was to form an insoluble complex with tannins during mixing in the presence of a stabilizer to facilitate nanoparticle self-assembly and impart stability. We use TA and bovine serum albumin (BSA) as a model system. Initially, we examined the precipitation of the BSA-TA complex via FNP. We mixed BSA dispersed in water with TA dissolved in acetone, which immediately formed a cloudy dispersion with a zeta potential of $-13.1 \pm 0.6 \mathrm{mV}$ (Table 1). Without a stabilizer, the precipitate continued to grow and macroscopic precipitation was observed within $24 \mathrm{~h}$. These observations indicate that BSA and TA complex and precipitate sufficiently fast upon mixing for nanoparticle self-assembly with FNP. We varied the ratio of BSA to TA (between 3:7 and 7:3 by mass) and observed the amount of macroscopic precipitate that formed. A mass ratio of 9:5 BSA to TA, produced the greatest amount of macroscopic precipitate (Figure S1a), and was thus used for subsequent experiments. 
Table 1. Zeta potential of BSA-TA complex with polymer stabilizers.

\begin{tabular}{cc}
\hline Sample & Zeta Potential $(\mathbf{m V})$ \\
\hline BSA-TA precipitate & $-13.1 \pm 0.6$ \\
BSA-TA with PS-b-PEG & $-18.0 \pm 3.0$ \\
PEI & $+34.3 \pm 4.2$ \\
BSA-TA with PEI & $+18.8 \pm 0.9$ \\
\hline
\end{tabular}

Based on these results of rapidly precipitating BSA with TA, we initially formulated nanoparticles using an amphiphilic block copolymer (PS-b-PEG) as a stabilizer. To perform FNP, BSA was dispersed in water and rapidly mixed with TA and PS-b-PEG which were dissolved in acetone. At a BSA to TA mass ratio of 9:5 and a block copolymer to core mass ratio of 2:1, the nanoparticle dispersion was polydisperse with multiple peaks at $\sim 100 \mathrm{~nm}, \sim 20 \mathrm{~nm}$, and $\sim 10 \mathrm{~nm}$ (Figure S2). The peaks can be attributed to TA/PS-b-PEG micelles [10], empty PS-b-PEG micelles [19], and soluble BSA [20], respectively. The lack of visible TA/BSA precipitate suggests that TA preferentially interacts with the block copolymer rather than with BSA during FNP. Further, there is a mismatch in timescales of complexation/precipitation and block copolymer micellization such that the block copolymer rapidly forms micelles and on a longer time scale stabilizes TA [10,21].

To promote BSA/TA interactions, we performed FNP with an excess of protein. When the BSA to TA ratio was increased to $4: 1$, nanoparticles were initially formed with a size of $\sim 600 \mathrm{~nm}$ with a PDI of $0.347 \pm 0.045$ similar to BSA-TA without stabilizer (Figure 1A,B). The measured zeta potential, $-18.0 \pm 3.0 \mathrm{mV}$, is consistent with other PEG based block copolymer stabilized nanoparticles [3,22]. Therefore, it appears that upon mixing BSA and TA complex and precipitate then the hydrophobic block of the amphiphilic block copolymer stabilizes the precipitate. TA also undergoes intermolecular interactions with the PEG block of the block copolymer via hydrogen bonding forming an insoluble complex that is confined to the nanoparticle core with the TA/BSA precipitate. The hydrophobic block of the block copolymer adsorbs to the precipitating nanoparticle core (hydrophobic PS-block, TA/BSA precipitate, TA:PEG) due to hydrophobic interactions. The PEG that is not complexed with TA microphase separates from the PS-block and orients into the aqueous phase providing steric stabilization. In this case, nanoparticle assembly is driven by a combination of hydrophobic and hydrogen bonding interactions.
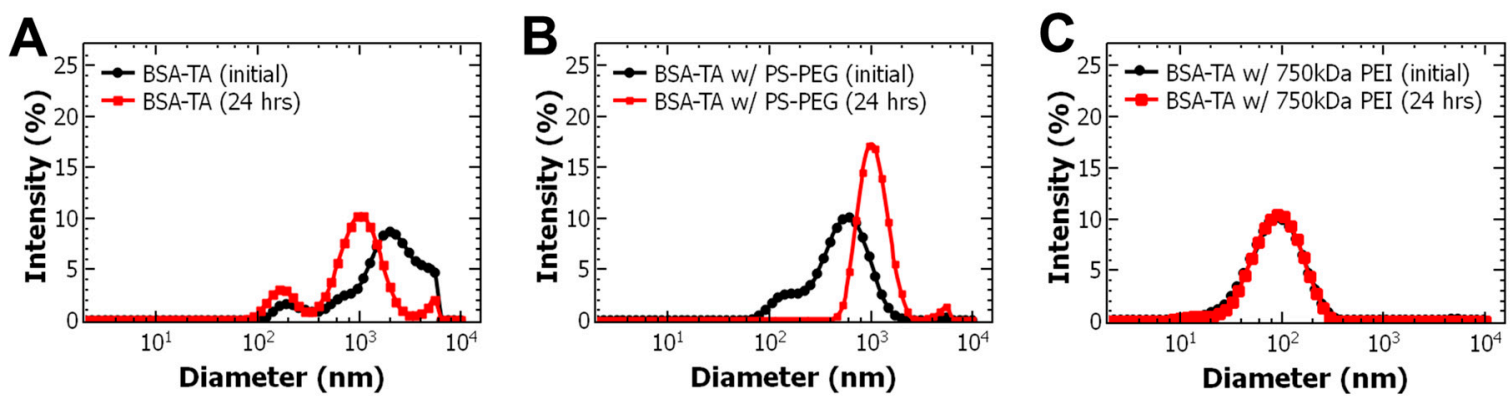

Figure 1. Dynamic light scattering (DLS) intensity weighted size distribution results of (A) bovine serum albumin-tannic acid (BSA-TA) complex without the presence of a stabilizer, (B) BSA-TA complex with an amphiphilic block copolymer, and (C) the BSA-TA complex stabilized with 750kDa polyethylenimine (PEI), immediately upon mixing and after $24 \mathrm{~h}$. The BSA-TA complex stabilized with PEI did not change in size after $24 \mathrm{~h}$.

While PS-b-PEG initially facilitated nanoparticle self-assembly, the resulting nanoparticle dispersion, initially transparent, turned cloudy over several hours indicating nanoparticle growth. Over $24 \mathrm{~h}$, TA and BSA partitioned out and re-precipitated outside of the nanoparticle core. Similar behavior has been observed with TA [10] and peptides [11] which is attributed to low affinity between the hydrophobic block of PS-b-PEG and the BSA/TA precipitate. 
Therefore, we next considered alternative stabilizers. Since we observed the initial BSA/TA complex showed a negative zeta potential of $-13.1 \pm 0.6 \mathrm{mV}$, we considered a cationic polyelectrolyte, polyethylenimine (PEI). To perform FNP, BSA dispersed in water was rapidly mixed with TA dissolved in acetone. The effluent of the mixer was immediately diluted into PEI with a molecular weight of $750,000 \mathrm{~g} / \mathrm{mol}(750 \mathrm{kDa}$ PEI) dispersed in water. The resulting nanoparticles were $107 \pm 5 \mathrm{~nm}$ with a PDI $0.285 \pm 0.004$ (Table 2). TEM imaging confirms that the particles are spherical and the size is consistent with DLS measurements (Figure S3). No macroscopic precipitate was observed over at least 7 days whereas macroscopic precipitate was observed within $24 \mathrm{~h}$ without a stabilizer (Figure 1C). Further, the zeta potential of the resulting $+18.8 \pm 0.9 \mathrm{mV}$ (Table 2) compared to $-13.1 \pm 0.6 \mathrm{mV}$ (Table 1) for BSA/TA without a stabilizer. The positive zeta potential suggests that PEI was present at the surface of the nanoparticles encapsulating the anionic BSA-TA precipitate providing some degree of steric stabilization as zeta potentials greater than $+35 \mathrm{mV}$ are required for entirely electrostatic stabilization [22]. Taken together, these results indicate that introducing the PEI stabilizer facilitated nanoparticle self-assembly and conferred nanoparticle stability.

Table 2. Effect of polyelectrolyte stabilizer molecular weight on nanoparticle properties and stability.

\begin{tabular}{ccccccc}
\hline \multirow{2}{*}{ Sample } & \multicolumn{3}{c}{ Initial } & \multicolumn{3}{c}{ 7 days } \\
\cline { 2 - 7 } & Zeta Potential $(\mathbf{m V})$ & Diameter $(\mathbf{n m})$ & PDI & Zeta Potential $(\mathbf{m V})$ & Diameter $(\mathbf{n m})$ & PDI \\
\hline $10 \mathrm{kDa}$ PEI & $+15.7 \pm 1.0$ & $153 \pm 7$ & $0.125 \pm 0.022$ & $+14.4 \pm 1.9$ & $152 \pm 1$ & $0.055 \pm 0.013$ \\
$750 \mathrm{kDa}$ PEI & $+18.5 \pm 1.3$ & $107 \pm 5$ & $0.285 \pm 0.004$ & $+18.5 \pm 1.3$ & $94 \pm 3$ & $0.259 \pm 0.011$ \\
\hline
\end{tabular}

Since stabilizer properties can greatly affect the resulting nanoparticle properties [3,23-25], we investigated the effect of PEI molecular weight (Table S2) on nanoparticle assembly and stability. We used molecular weights of $750 \mathrm{kDa}, 10 \mathrm{kDa}$, and $2 \mathrm{kDa}$. Interestingly, while $750 \mathrm{kDa}$ PEI resulted in $107 \pm 5 \mathrm{~nm}$ stable nanoparticle, $10 \mathrm{kDa}$ PEI formed monodisperse, stable particles with a diameter of $153 \pm 7 \mathrm{~nm}$ with a PDI of $0.125 \pm 0.022$ and a zeta potential $+14.4 \pm 1.9 \mathrm{mV}$ (Table 2, Figure S4). The $2 \mathrm{kDa}$ PEI did not facilitate nanoparticle assembly (Table S3) and FNP resulted in macroscopic precipitate. Thus, PEI molecular weights $10 \mathrm{kDa}$ or greater were necessary for nanoparticle formation via self-assembly to encapsulate the BSA/TA complex. High molecular weight polyelectrolytes have been reported to strongly absorb onto surfaces which improve the stabilization of dispersions [26,27] such as the BSA/TA precipitate. In contrast, lower molecular weight polyelectrolytes have higher intermolecular charge repulsion which limits the electrostatic stabilization of the BSA/TA precipitate [27].

We confirmed the role of electrostatic interactions in nanoparticle assembly and stabilization by examining the effect of $\mathrm{pH}$ of the BSA stream on particle formation. First, we confirmed TA precipitates $\mathrm{BSA}$ at various $\mathrm{pH}$ conditions; we observed macroscopic precipitation for $\mathrm{pH}$ between 7 and 4.5, and no visible precipitate at $\mathrm{pH} 2$ (Figure S1b). The maximum amount of visible BSA-TA precipitate was produced around $\mathrm{pH} 5$ which can be attributed to protein aggregation near the isoelectric point of BSA ( $\mathrm{pI}=4.8$ ) [28] comparable to previous reports [14]. Subsequently, the $\mathrm{pH}$ of the BSA stream was adjusted to between 2 and 10 prior to FNP while the PEI reservoir was unbuffered $(\mathrm{pH} \sim 10)$ and the nanoparticle size and zeta potential were examined. Varying the $\mathrm{pH}$ of the BSA stream did not change the size or zeta potential of the $750 \mathrm{kDa}$ PEI NPs (Table S4) indicating the measured properties are dictated by the PEI. Interestingly, decreasing the $\mathrm{pH}$ to 2 using $10 \mathrm{kDa}$ PEI disrupted particle assembly (Figure S5, Table S5) and instead formation of a visible precipitate was observed. The net charge of BSA is dependent on $\mathrm{pH}$; decreasing $\mathrm{pH}$ below the isoelectric point results in protonation of the protein and a net positive charge [14,16]. With a net positive charge, BSA repels the cationic PEI (pKa 10) [26,29] and thus particles do not form. Therefore, particle assembly requires the $\mathrm{pH}$ to be at or above the isoelectric point of the protein (i.e., $\mathrm{pH}>5$ ) to ensure electrostatic interaction with the PEI stabilizer.

Based on these results, we propose that the mechanism of nanoparticle self-assembly differs between the $10 \mathrm{kDa}$ and the $750 \mathrm{kDa}$ PEI. Interestingly, $750 \mathrm{kDa}$ PEI NPs have a size of $\sim 100 \mathrm{~nm}$, similar to the hydrodynamic diameter of $750 \mathrm{kDa}$ PEI (Table S2). Therefore, the high molecular weight PEI 
aggregates and these aggregates serve as the nanoparticle template and a sink for absorbing the anionic BSA/TA complex. In contrast, nanoparticles formulated with $10 \mathrm{kDa}$ PEI $(\sim 150 \mathrm{~nm})$ are much larger than their corresponding polymer in aqueous media $(\sim 5 \mathrm{~nm})$. For this stabilizer, BSA/TA complex and precipitate. Particle assembly occurs as cationic $10 \mathrm{kDa}$ PEI adsorbs to the anionic BSA/TA precipitate via electrostatic interactions. This mechanism of nanoparticle self-assembly is analogous to previous work with FNP encapsulating coordination complexes or ion pairs formed during mixing [7,10-12,30]. Schematics of the particle self-assembly mechanisms for the $750 \mathrm{kDa}$ and $10 \mathrm{kDa}$ PEI are shown in Figure 2.

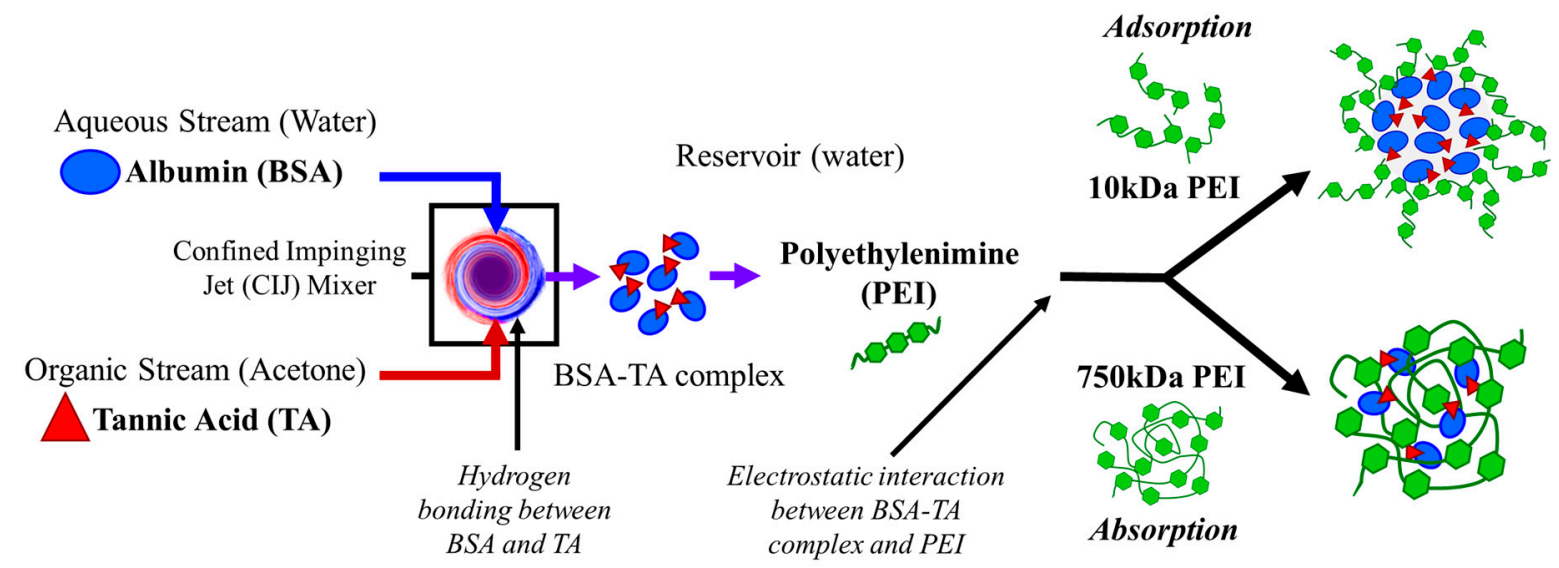

Figure 2. Schematic of the proposed self-assembly mechanisms using $750 \mathrm{kDa}$ and $10 \mathrm{kDa}$ polyethylenimine (PEI) via flash nanoprecipitation (FNP) with PEI stabilizer. In the confined impinging jet (CIJ) mixer the bovine serum albumin (BSA) and tannic acid (TA) interact via hydrogen bonding to form an insoluble complex. Then the complex is immediately diluted in a reservoir containing PEI. The BSA-TA complex interacts with the PEI via electrostatic interaction. High molecular weight $750 \mathrm{kDa}$ PEI aggregates template nanoparticle assembly and absorb the BSA-TA precipitate. In contrast, $10 \mathrm{kDa}$ PEI adsorbs on the precipitating BSA-TA complex forming a core-shell structure.

Building on these results, we next sought to understand the effect of formulation parameters on nanoparticle assembly, specifically nanoparticle size. Typically, when nanoparticle assembly occurs due to hydrophobic interactions between the precipitation core material and micellizing block copolymer, the nanoparticle size can be tuned with the mass ratio of the block copolymer to the core materials as well as the total solids concentration [31].

The mass ratio of PEI to BSA-TA complex was adjusted from 3:1 to 2:1. However, for the $750 \mathrm{kDa}$ PEI, decreasing the relative amount of stabilizer resulted in unstable nanoparticles with visible precipitate forming within $24 \mathrm{~h}$ (Table S6a). For the $10 \mathrm{kDa}$ PEI, stable particles were achieved with lower relative amounts of stabilizer. While the size was not significantly affected, the PDI increased indicating less uniform particles (Table S7). Overall, we observe that the range of stabilizer to core ratio that forms stable, uniform nanoparticles is relatively narrow compared to the range used with hydrophobic interactions driving nanoparticle self-assembly. This finding is consistent with particle formation involving in situ coordination complexation [10] or cationic polysaccharides [32]. A ratio of 3:1 PEI to BSA-TA complex was used for subsequent experiments.

To vary particle size, the total solids concentration of the BSA, TA, and PEI in the final dispersion was varied from $5.6 \mathrm{mg} / \mathrm{mL}$ to $11.2 \mathrm{mg} / \mathrm{mL}$; the $9: 5$ ratio of BSA:TA and 3:1 ratio of PEI:BSA/TA were held constant. We note that with the $750 \mathrm{kDa}$ PEI stabilizer, the total solids concentration did not affect particle size or stability (Table S6b). Using $750 \mathrm{kDa}$ PEI as a stabilizer, particle assembly was templated by the aggregated polymer $[27,29,33]$. The results are comparable to previous reports with various PEI systems at constant charge ratios [34,35]. Interestingly, with the $10 \mathrm{kDa}$ PEI stabilizer, doubling the total solids concentration resulted in a two-fold increase in particle size from $143 \pm 8 \mathrm{~nm}$ 
to $319 \pm 185 \mathrm{~nm}$ while maintaining a PDI less than 0.300 (Table S7). The trend of increasing size with total solids concentration is comparable to previous results with FNP [1,31].

Traditionally, FNP involves an amphiphilic block copolymer and hydrophobic core materials. Upon mixing, the rapid decrease in solvent quality leads to simultaneous precipitation of the hydrophobic core material via nucleation and growth and self-assembly of the amphiphilic block copolymer. Nanoparticle assembly is arrested when sufficient hydrophobic block of the amphiphilic block copolymer adsorbs to the precipitating core material preventing further nanoparticle growth and the nanoparticle is sterically stabilized by the water-soluble block of the block copolymer. Typically, the nanoparticle size can be affected by varying the total mass concentration. Specifically, increasing the total mass concentration leads to an increase in particle size which has been attributed to a greater rate of core growth relative to the rate of nucleation which results in larger particle size [1,31]. In this case, the mechanism of particle self-assembly is analogous to traditional FNP because BSA/TA complexation and subsequent precipitation via nucleation and growth is sufficiently fast relative to adsorption of the PEI stabilizer. Thus, these results support the mechanism of particle self-assembly in which TA precipitates the protein and further precipitation is arrested by adsorption of the $10 \mathrm{kDa}$ PEI stabilizer.

Salt and $\mathrm{pH}$ are expected to greatly affect electrostatic assemblies [36], thus we examined nanoparticle stability as a function of $\mathrm{pH}$ and ionic strength. After mixing, the nanoparticle dispersion had a $\mathrm{pH}$ of $\sim 10$ due to the PEI. As expected, decreasing the $\mathrm{pH}$ to 2 caused the nanoparticles with the $10 \mathrm{kDa}$ PEI stabilizer to disassemble, as indicated by DLS. The presence of a peak on the order of $10 \mathrm{~nm}$ can be attributed to unencapsulated BSA [20] (Figure 3A). At acidic conditions, protonation of PEI and BSA leads to a net positive charge on both molecules and charge repulsion, which destabilizes the particles. Similar results were observed after dialysis of the nanoparticles against deionized water (Figure S6) due to decrease in $\mathrm{pH}$ near the isoelectric point of BSA. Therefore, the $\mathrm{pH}$ of the nanoparticle dispersion should be greater than the isoelectric point of the protein to maintain particle stability. Surprisingly, the particles using the $750 \mathrm{kDa}$ stabilizer were stable below the isoelectric point of BSA $(\mathrm{pH}<4.8)$ when both the PEI and BSA are expected to carry a net positive charge (Figure 3B). The PEI aggregates may provide a localized buffering effect preventing protonation of BSA [29].
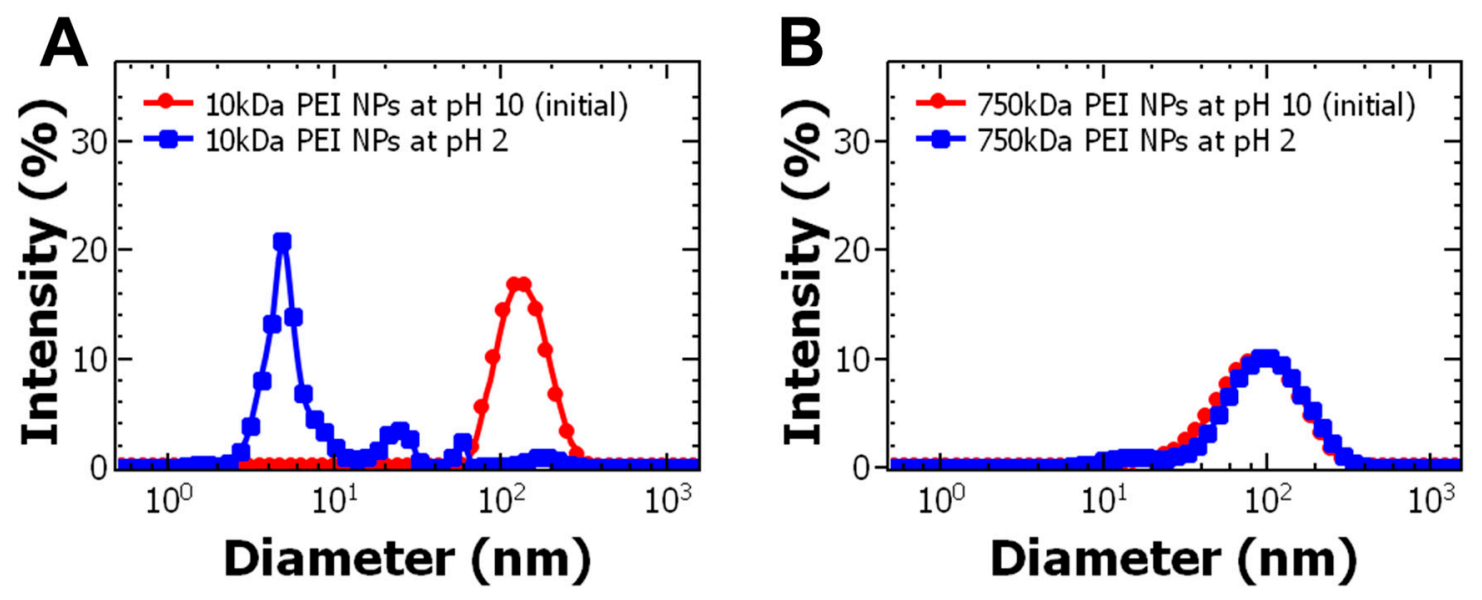

Figure 3. Effect of nanoparticle dispersion $\mathrm{pH}$ on size for (A) $10 \mathrm{kDa}$ polyethylenimine nanoparticles (PEI NPs) and (B) $750 \mathrm{kDa}$ PEI NPs. The size of the particles was measured $24 \mathrm{~h}$ after adjusting the $\mathrm{pH}$. The $10 \mathrm{kDa}$ PEI NPs destabilized under acidic conditions and released bovine serum albumin (BSA). The $750 \mathrm{kDa}$ PEI NPs did not change size at acidic $\mathrm{pH}$.

To further understand particle stability, we investigated the effect of adjusting the ionic strength of the particle dispersion between $0.01 \mathrm{M}$ to $0.3 \mathrm{M}$ with monovalent and divalent salts. With the $750 \mathrm{kDa}$ PEI stabilizer, the measured size decreased slightly in the presence of salt at ionic strengths greater than $0.01 \mathrm{M}$ (Table S8). The decrease in particle size with ionic strength has been observed previously 
and was attributed to decreased intra-molecular charge repulsion forces which allow for tighter PEI aggregate formation [29].

In the presence of $\mathrm{NaCl}$, the size of $10 \mathrm{kDa}$ PEI stabilized nanoparticles was not affected at ionic strengths less than $0.03 \mathrm{M}$ and increased two-fold at an ionic strength of $0.3 \mathrm{M}$. The presence of salts introduce charge screening and reduce the electrostatic interactions between the $10 \mathrm{kDa}$ PEI stabilizer and anionic TA/BSA precipitate leading to the increase in particle size [27,37]. Interestingly, the diameter of the $10 \mathrm{kDa}$ PEI stabilized nanoparticles was $290 \pm 6 \mathrm{~nm}$ in the presence of $\mathrm{NaCl}$, compared to $188 \pm 7 \mathrm{~nm}$ with $\mathrm{CaCl}_{2}$ at the same ionic strength $(0.3 \mathrm{M})$ (Table 3). The difference in particle size in the presence of $\mathrm{Ca}^{2+}$ and $\mathrm{Na}^{+}$ions at the same ionic strength can be attributed to a 3-fold difference in ion concentration of $\mathrm{Na}^{+}$ions compared to $\mathrm{Ca}^{2+}$ which resulted in greater charge screening and thus larger particle size. Additionally, calcium promotes protein/TA precipitation compared to sodium [16] and specific BSA-calcium interactions promote BSA aggregation compared to sodium [38], which prevents particle swelling.

Table 3. Effect of ionic strength on $10 \mathrm{kDa}$ PEI nanoparticle properties.

\begin{tabular}{cccccc}
\hline Salt Added & Concentration $(\mathbf{m M})$ & Ionic Strength $(\mathbf{M})$ & Diameter $(\mathbf{n m})$ & PDI & Zeta Potential $(\mathbf{m V})$ \\
\hline Initial 10 kDa & 0 & 0 & $146 \pm 2$ & $0.125 \pm 0.020$ & $15.7 \pm 2.0$ \\
PEI & 10 & 0.01 & $145 \pm 2$ & $0.065 \pm 0.019$ & $13.5 \pm 2.6$ \\
$\mathrm{NaCl}$ & 30 & 0.03 & $139 \pm 2$ & $0.069 \pm 0.007$ & $13.4 \pm 2.0$ \\
& 100 & 0.1 & $194 \pm 3$ & $0.035 \pm 0.023$ & $14.3 \pm 0.3$ \\
& 300 & 0.3 & $290 \pm 6$ & $0.110 \pm 0.024$ & $11.8 \pm 1.4$ \\
$\mathrm{CaCl}_{2}$ & 10 & 0.03 & $138 \pm 6$ & $0.351 \pm 0.019$ & $15.8 \pm 1.0$ \\
& 100 & 0.3 & $188 \pm 7$ & $0.148 \pm 0.022$ & $16.1 \pm 0.5$ \\
\hline
\end{tabular}

Taken together, these results demonstrate that self-assembled nanoparticles are stable at physiologically relevant ionic strengths $(\sim 0.15 \mathrm{M})$. The particles are $\mathrm{pH}$ labile. Specifically, they are stable at basic $\mathrm{pH}$ (e.g., 7.4) and disassemble at acidic $\mathrm{pH}$. Such properties may be promising for controlled release application such as intracellular delivery [10,39-41].

Finally, we quantified the amount of BSA in the nanoparticles in terms of encapsulation efficiency and protein loading for both molecular weights of PEI via Bradford assay. To understand the role of TA in nanoparticle assembly, we compared formulations with and without TA. Interestingly, while TA did not affect particle size or zeta potential (Table S9), it greatly affected the amount of protein incorporated into the nanoparticles (Table 4). For example, using the $750 \mathrm{kDa}$ PEI stabilizer, the protein encapsulation increased from $50 \%$ with TA to $74 \%$ without the presence of TA. This result suggests that the charge density of BSA alone compared to the BSA/TA complex enhances interactions with PEI. Additionally, the absence of TA may increase BSA-PEI interactions. In contrast, with the $10 \mathrm{kDa}$ PEI NPs, the protein encapsulation increased from $8 \%$ without TA to $79 \%$ with TA. This result supports the mechanism of self-assembly in which TA/BSA complex and precipitate and further growth of the precipitate is prevented by adsorption of the $10 \mathrm{kDa}$ PEI stabilizer.

Table 4. Effect of tannic acid (TA) on protein encapsulation.

\begin{tabular}{cccc}
\hline Sample & Condition & Encapsulation Efficiency (EE\%) & Drug Loading (DL\%) \\
\hline \multirow{2}{*}{10 kDa PEI NPs } & no TA & $8 \% \pm 3 \%$ & $1 \% \pm 0 \%$ \\
& with TA & $79 \% \pm 7 \%$ & $13 \% \pm 1 \%$ \\
\hline \multirow{2}{*}{750 kDa PEI NPs } & no TA & $74 \% \pm 6 \%$ & $12 \% \pm 1 \%$ \\
& with TA & $50 \% \pm 10 \%$ & $8 \% \pm 2 \%$ \\
\hline
\end{tabular}

Interestingly, the $10 \mathrm{kDa}$ PEI stabilizer resulted in higher protein loading (13\% compared to $8 \%$ ) and encapsulation efficiency (79\% compared to 50\%) than achieved with the $750 \mathrm{kDa}$ PEI stabilizer (Table 4). Nanoparticle assembly using the $10 \mathrm{kDa}$ PEI that occurs due to adsorption of the stabilizer to the 
precipitate forms kinetically trapped and enhances protein encapsulation compared to the absorption of the precipitate with the $750 \mathrm{kDa}$ PEI aggregates. This improvement in loading is analogous to traditional FNP with hydrophobic small molecules [42]. Excitingly, the encapsulation efficiency of protein via rapid mixing with $10 \mathrm{kDa}$ PEI is greater $(\sim 80 \%)$ than generally reported for encapsulating biologics via nanoprecipitation $(7 \%-40 \%)[11,43]$. These results suggest that FNP facilitated by TA/BSA complexation and precipitation is a highly efficient, rapid process for encapsulating proteins. Alternatively, we demonstrate it is possible to encapsulate protein via FNP without the need of precipitation using the 750 kDa PEI stabilizer.

\section{Conclusions}

Overall, we have demonstrated a rapid, single-step method using Flash NanoPrecipitation for encapsulating biologics (i.e., proteins) with high encapsulation efficiency (up to $\sim 80 \%$ ). Using the $10 \mathrm{kDa}$ PEI stabilizer, nanoparticle formation involves complexation and precipitation with tannic acid and stabilization with a cationic polyelectrolyte. Nanoparticle self-assembly is driven by hydrogen bonding between TA and protein, then electrostatic interactions between the TA/protein precipitate and polyelectrolyte stabilizer. The resulting particles are stable at physiological ionic strengths and $\mathrm{pH}$ labile, i.e., stable above the isoelectric point of the protein and disassemble at $\mathrm{pH}$ below the isoelectric point of the protein, to facilitate potential controlled release applications.

Supplementary Materials: The following are available online at http://www.mdpi.com/2073-4360/11/9/1406/s1, Table S1: BSA recovery; Table S2: Size and zeta potential of PEI dispersed in water; Table S3: Effect of PEI molecular weight on nanoparticle formulation; Table S4: Effect of $\mathrm{pH}$ of the BSA stream and PEI reservoir on $750 \mathrm{kDa}$ PEI nanoparticles; Table S5: Effect of $\mathrm{pH}$ of the BSA stream and PEI reservoir on $10 \mathrm{kDa}$ PEI NPs formulation; Table S6a: Varying ratio of stabilizer to core for $750 \mathrm{kDa}$ PEI nanoparticles; Table S6b: Varying total solids of $750 \mathrm{kDa}$ PEI nanoparticles; Table S7: Varying total solids concentration and ratio of BSA to TA by mass for nanoparticles made with 10 kDa PEI; Table S8: Effect of ionic strength on particle stability of 750 kDa PEI nanoparticles; Table S9: Effect of TA on nanoparticle formulation; Figure S1a: Precipitation of BSA and TA—varying BSA:TA ratio; Figure S1b: Precipitation of BSA and TA—varying pH; Figure S2: Nanoparticles formulated with PS-b-PEG $(28 \mathrm{mg} / \mathrm{mL})$ and TA $(5 \mathrm{mg} / \mathrm{mL})$ dissolved in acetone and rapidly mixed with BSA $(9 \mathrm{mg} / \mathrm{mL})$ dispersed in water via FNP; Figure S3: TEM of BSA/TA nanoparticles stabilized by $750 \mathrm{kDa}$ PEI; Figure S4: Effect of PEI molecular weight on nanoparticle formulation; Figure S5: DLS of the $10 \mathrm{kDa}$ PEI nanoparticles formulated under different pH conditions; Figure S6: DLS of $10 \mathrm{kDa}$ PEI nanoparticles after dialysis.

Author Contributions: Conceptualization, S.L.L. and C.T.; Formal analysis, S.L.L., R.C.W. and C.T.; Funding acquisition, C.T.; Investigation, S.L.L. and R.C.W.; Methodology, S.L.L. and R.C.W.; Project administration, C.T.; Resources, C.T.; Supervision, S.L.L. and C.T.; Validation, S.L.L., R.C.W. and C.T.; Writing-original draft, S.L.L. and C.T.; Writing-review \& editing, S.L.L., R.C.W. and C.T.

Funding: This work was partially supported by startup funding at Virginia Commonwealth University, and NSF (Award number 1651957).

Acknowledgments: The authors gratefully acknowledge Stephen S. Fong, Nastassja A. Lewinski, and Judy Williamson for instrumental support and Raven Smith for her assistance with experiments. Microscopy was performed at the VCU Microscopy Facility, supported, in part, by funding from NIH-NCI Cancer Center Support Grant P30 CA016059.

Conflicts of Interest: The authors declare no conflict of interest. The funders had no role in the design of the study; in the collection, analyses, or interpretation of data; in the writing of the manuscript, or in the decision to publish the results.

\section{References}

1. Tang, C.; Prud'homme, R.K. Targeted Theragnostic Nanoparticles Via Flash Nanoprecipitation: Principles of Material Selection. In Polymer Nanoparticles for Nanomedicines: A Guide for their Design, Preparation and Development; Vauthier, C., Ponchel, G., Eds.; Springer: Basel, Switzerland, 2016; pp. 55-85, ISBN 978-3-319-41421-8. [CrossRef]

2. Zhang, C.; Pansare, V.J.; Prud'homme, R.K.; Zhang, C.; Priestley, R.D. Flash nanoprecipitation of polystyrene nanoparticles. Soft Matter 2012, 8, 86-93. [CrossRef] 
3. Pustulka, K.M.; Wohl, A.R.; Lee, H.S.; Michel, A.R.; Han, J.; Hoye, T.R.; McCormick, A.V.; Panyam, J.; Macosko, C.W. Flash nanoprecipitation: Particle structure and stability. Mol. Pharm. 2013, 10, 4367-4377. [CrossRef] [PubMed]

4. Calo-Fernández, B.; Martínez-Hurtado, J.L. Biosimilars: Company Strategies to Capture Value from the Biologics Market. Pharmaceuticals 2012, 5, 1393-1408. [CrossRef] [PubMed]

5. Sato, A.K.; Viswanathan, M.; Kent, R.B.; Wood, C.R. Therapeutic peptides: Technological advances driving peptides into development. Curr. Opin. Biotechnol 2006, 17, 638-642. [CrossRef] [PubMed]

6. Desai, N. Challenges in Development of Nanoparticle-Based Therapeutics. AAPS J 2012, 14, $282-295$. [CrossRef] [PubMed]

7. Pinkerton, N.M.; Behar, L.; Hadri, K.; Amouroux, B.; Mingotaud, C.; Talham, D.R.; Chassaing, S.; Marty, J.-D. Ionic Flash NanoPrecipitation (iFNP) for the facile, one-step synthesis of inorganic-organic hybrid nanoparticles in water. Nanoscale 2017, 9, 1403-1408. [CrossRef] [PubMed]

8. Pinkerton, N.M.; Hadri, K.; Amouroux, B.; Behar, L.; Mingotaud, C.; Destarac, M.; Kulai, I.; Mazières, S.; Chassaing, S.; Marty, J.-D. Quench ionic flash nano precipitation as a simple and tunable approach to decouple growth and functionalization for the one-step synthesis of functional LnPO 4 -based nanoparticles in water. Chem. Commun. 2018, 54, 9438-9441. [CrossRef] [PubMed]

9. Pinkerton, N.M.; Grandeury, A.; Fisch, A.; Brozio, J.; Riebesehl, B.U.; Prud'homme, R.K. Formation of Stable Nanocarriers by in Situ Ion Pairing during Block-Copolymer-Directed Rapid Precipitation. Mol. Pharm. 2013, 10, 319-328. [CrossRef] [PubMed]

10. Tang, C.; Amin, D.; Messersmith, P.B.; Anthony, J.E.; Prud'homme, R.K. Polymer Directed Self-Assembly of pH-Responsive Antioxidant Nanoparticles. Langmuir 2015, 31, 3612-3620. [CrossRef] [PubMed]

11. Pagels, R.F.; Prud'homme, R.K. Polymeric nanoparticles and microparticles for the delivery of peptides, biologics, and soluble therapeutics. J. Control. Release 2015, 219, 519-535. [CrossRef]

12. Markwalter, C.E.; Prud'homme, R.K. Design of a Small-Scale Multi-Inlet Vortex Mixer for Scalable Nanoparticle Production and Application to the Encapsulation of Biologics by Inverse Flash NanoPrecipitation. J. Pharm. Sci. 2018, 107, 2465-2471. [CrossRef] [PubMed]

13. Santos, J.L.; Ren, Y.; Vandermark, J.; Archang, M.M.; Williford, J.-M.; Liu, H.-W.; Lee, J.; Wang, T.-H.; Mao, H.-Q. Continuous Production of Discrete Plasmid DNA-Polycation Nanoparticles Using Flash Nanocomplexation. Small 2016, 12, 6214-6222. [CrossRef] [PubMed]

14. Van Buren, J.P.; Robinson, W.B. Formation of Complexes between Protein and Tannic Acid. J. Agric. Food Chem. 1969, 17, 772-777. [CrossRef]

15. Hagerman, A.E.; Butler, L.G. Determination of Protein in Tannin-Protein Precipitates. J. Agric. Food Chem. 1980, 28, 944-947. [CrossRef] [PubMed]

16. Martin, M.M.; Rockholm, D.C.; Martin, J.S. Effects of surfactants, pH, and certain cations on precipitation of proteins by tannins. J. Chem. Ecol. 1985, 11, 485-494. [CrossRef]

17. Levit, S.L.; Stwodah, R.M.; Tang, C. Rapid, Room Temperature Nanoparticle Drying and Low-Energy Reconstitution via Electrospinning. J. Pharm. Sci. 2018, 107, 807-813. [CrossRef] [PubMed]

18. Nanocomposix's Guide to Dynamic Light Scattering Measurement and Analysis 2015. Available online: http://50.87.149.212/sites/default/files/nanoComposix\%20Guidelines\%20for\%20DLS\%20Measurements\% 20and\%20Analysis.pdf (accessed on 24 July 2019).

19. Johnson, B.K.; Prud homme, R.K. Flash NanoPrecipitation of Organic Actives and Block Copolymers using a Confined Impinging Jets Mixer. Aust. J. Chem. 2003, 56, 1021-1024. [CrossRef]

20. Meechai, N.; Jamieson, A.M.; Blackwell, J. Translational Diffusion Coefficients of Bovine Serum Albumin in Aqueous Solution at High Ionic Strength. J. Colloid Interface Sci. 1999, 218, 167-175. [CrossRef] [PubMed]

21. Johnson, B.K.; Prud'homme, R.K. Mechanism for Rapid Self-Assembly of Block Copolymer Nanoparticles. Phys. Rev. Lett. 2003, 91, 118302. [CrossRef] [PubMed]

22. Tang, C.; Sosa, C.L.; Pagels, R.F.; Priestley, R.D.; Prud'homme, R.K. Efficient preparation of size tunable PEGylated gold nanoparticles. J. Mater. Chem. B 2016, 4, 4813-4817. [CrossRef]

23. Saad, W.S.; Prud'homme, R.K. Principles of nanoparticle formation by flash nanoprecipitation. Nano Today 2016, 11, 212-227. [CrossRef]

24. Zhu, Z. Effects of amphiphilic diblock copolymer on drug nanoparticle formation and stability. Biomaterials 2013, 34, 10238-10248. [CrossRef] [PubMed] 
25. Kumar, V.; Wang, L.; Riebe, M.; Tung, H.-H.; Prud'homme, R.K. Formulation and stability of itraconazole and odanacatib nanoparticles: Governing physical parameters. Mol. Pharm. 2009, 6, 1118-1124. [CrossRef] [PubMed]

26. Dietrich, A.; Neubrand, A. Effects of Particle Size and Molecular Weight of Polyethylenimine on Properties of Nanoparticulate Silicon Dispersions. J. Am. Ceram. Soc. 2001, 84, 806-812. [CrossRef]

27. Lindquist, G.M.; Stratton, R.A. The role of polyelectrolyte charge density and molecular weight on the adsorption and flocculation of colloidal silica with polyethylenimine. J. Colloid Interface Sci. 1976, 55, 45-59. [CrossRef]

28. Shi, Q.; Zhou, Y.; Sun, Y. Influence of $\mathrm{pH}$ and ionic strength on the steric mass-action model parameters around the isoelectric point of protein. Biotechnol. Prog. 2005, 21, 516-523. [CrossRef] [PubMed]

29. Curtis, K.A.; Miller, D.; Millard, P.; Basu, S.; Horkay, F.; Chandran, P.L. Unusual Salt and pH Induced Changes in Polyethylenimine Solutions. PLoS ONE 2016, 11, 1-20. [CrossRef]

30. Jo, A.; Zhang, R.; Allen, I.C.; Riffle, J.S.; Davis, R.M. Design and Fabrication of Streptavidin-Functionalized, Fluorescently Labeled Polymeric Nanocarriers. Langmuir 2018, 34, 15783-15794. [CrossRef]

31. Pagels, R.F.; Edelstein, J.; Tang, C.; Prud'homme, R.K. Controlling and Predicting Nanoparticle Formation by Block Copolymer Directed Rapid Precipitations. Nano Lett. 2018, 18, 1139-1144. [CrossRef]

32. Zhu, Z.; Margulis-Goshen, K.; Magdassi, S.; Talmon, Y.; Macosko, C.W. Polyelectrolyte stabilized drug nanoparticles via flash nanoprecipitation: A model study with beta-carotene. J. Pharm. Sci. 2010, 99, 4295-4306. [CrossRef]

33. Kosacheva, E.M.; Kudryavtsev, D.B.; Bakeeva, R.F.; Kuklin, A.I.; Islamov, A.K.; Kudryavtseva, L.A.; Sopin, V.F.; Konovalov, A.I. The aggregation of branched polyethylenimine and cationic surfactants in aqueous systems. Colloid J. 2006, 68, 713-720. [CrossRef]

34. Zhang, M.; Xue, Y.-N.; Liu, M.; Zhuo, R.-X.; Huang, S.-W. Biocleavable Polycationic Micelles as Highly Efficient Gene Delivery Vectors. Nanoscale Res. Lett. 2010, 5, 1804-1811. [CrossRef]

35. Dai, Z.; Wu, C. How Does DNA Complex with Polyethylenimine with Different Chain Lengths and Topologies in Their Aqueous Solution Mixtures? Macromolecules 2012, 45, 4346-4353. [CrossRef]

36. Blocher, W.C.; Perry, S.L. Complex coacervate-based materials for biomedicine. Wiley Interdiscip. Rev. Nanomed. Nanobiotechnol. 2017, 9. [CrossRef]

37. Salt-Induced Charge Screening and Significant Conductivity Enhancement of Conducting Poly(3,4-ethylenedioxythiophene):Poly(styrenesulfonate)—Macromolecules (ACS Publications). Available online: https://pubs.acs.org/doi/10.1021/ma900327d (accessed on 14 February 2019).

38. Donato, L.; Garnier, C.; Doublier, J.-L.; Nicolai, T. Influence of the $\mathrm{NaCl}$ or $\mathrm{CaCl}_{2}$ Concentration on the Structure of Heat-Set Bovine Serum Albumin Gels at pH 7. Biomacromolecules 2005, 6, 2157-2163. [CrossRef]

39. Meng, F.; Zhong, Y.; Cheng, R.; Deng, C.; Zhong, Z. pH-sensitive polymeric nanoparticles for tumor-targeting doxorubicin delivery: Concept and recent advances. Nanomedicine 2014, 9, 487-499. [CrossRef]

40. Lynn, D.M.; Amiji, M.M.; Langer, R. pH-Responsive Polymer Microspheres: Rapid Release of Encapsulated Material within the Range of Intracellular pH. Angew. Chem. Int. Ed. 2001, 40, 1707-1710. [CrossRef]

41. Du, J.-Z.; Du, X.-J.; Mao, C.-Q.; Wang, J. Tailor-Made Dual pH-Sensitive Polymer-Doxorubicin Nanoparticles for Efficient Anticancer Drug Delivery. J. Am. Chem. Soc. 2011, 133, 17560-17563. [CrossRef]

42. Kumar, V.; Prud'homme, R.K. Thermodynamic limits on drug loading in nanoparticle cores. J. Pharm. Sci. 2008, 97, 4904-4914. [CrossRef]

43. Barichello, J.M.; Morishita, M.; Takayama, K.; Nagai, T. Encapsulation of Hydrophilic and Lipophilic Drugs in PLGA Nanoparticles by the Nanoprecipitation Method. Drug Dev. Ind. Pharm. 1999, 25, 471-476. [CrossRef]

(C) 2019 by the authors. Licensee MDPI, Basel, Switzerland. This article is an open access article distributed under the terms and conditions of the Creative Commons Attribution (CC BY) license (http://creativecommons.org/licenses/by/4.0/). 